\title{
Dendritic epidermal T cells regulate skin antimicrobial barrier function
}

\author{
Amanda S. MacLeod, ${ }^{1}$ Saskia Hemmers, ${ }^{1,2}$ Olivia Garijo, ${ }^{1}$ Marianne Chabod, ${ }^{1}$ \\ Kerri Mowen, ${ }^{1,2}$ Deborah A. Witherden, ${ }^{1}$ and Wendy L. Havran ${ }^{1}$
}

${ }^{1}$ Department of Immunology and Microbial Science and 2Department of Chemical Physiology, The Scripps Research Institute, La Jolla, California, USA.

\begin{abstract}
The epidermis, the outer layer of the skin, forms a physical and antimicrobial shield to protect the body from environmental threats. Skin injury severely compromises the epidermal barrier and requires immediate repair. Dendritic epidermal $T$ cells (DETC) reside in the murine epidermis where they sense skin injury and serve as regulators and orchestrators of immune responses. Here, we determined that TCR stimulation and skin injury induces IL-17A production by a subset of DETC. This subset of IL-17A-producing DETC was distinct from IFN- $\gamma$ producers, despite similar surface marker profiles. Functionally, blocking IL-17A or genetic deletion of IL-17A resulted in delayed wound closure in animals. Skin organ cultures from $\mathrm{Tcrd}^{-/}$, which lack DETC, and $\mathrm{Il}_{17 \mathrm{a}^{-/}}$mice both exhibited wound-healing defects. Wound healing was fully restored by the addition of WT DETC, but only partially restored by IL-17A-deficient DETC, demonstrating the importance of IL-17A to wound healing. Following skin injury, DETC-derived IL-17A induced expression of multiple host-defense molecules in epidermal keratinocytes to promote healing. Together, these data provide a mechanistic link between IL-17A production by DETC, host-defense, and wound-healing responses in the skin. These findings establish a critical and unique role of IL-17A-producing DETC in epidermal barrier function and wound healing.
\end{abstract}

\section{Introduction}

The epidermis forms the outer barrier of the body and is an initial site of host immune responses and defense mechanisms against environmental and pathogenic insults (1). The expression of antimicrobial peptides and proteins (AMP) is a key element of the biochemical skin barrier, and multiple AMP, including cathelicidins, $\beta$-defensins, and S100 proteins, have been identified and shown to play roles in wound healing and defense against pathogens and malignancy (2-4). Disturbance of the skin barrier upon injury predisposes to infection and requires immediate reestablishment of the biochemical and physical skin barrier. This is accomplished by a sequential series of events, including inflammation, epithelial cell proliferation, and tissue remodeling (5-7). Studies in humans and mice have shown that IL-17 can induce several epithelial AMP (8). Importantly, IL-17A increases following breaching of the skin barrier before infiltration of peripheral $\mathrm{T}$ cells into the wound bed $(9,10)$, and AMP are released by keratinocytes early upon skin injury (11-14), suggesting a relevant role for local IL-17A production in the cutaneous wound-healing response.

Specialized intraepithelial lymphocytes (IEL) reside at sites where the body's surface is at the interface with the external environment, such as the epidermis or mucosa. Mouse epidermis contains large numbers of such prototypic IEL, called dendritic epidermal T cells (DETC). DETC express an invariant V $\gamma 3 \mathrm{~V} \delta 1$ TCR (nomenclature according to Garman; ref. 15) and are the only resident T cell population in the mouse epidermis, emphasizing their crucial role in keratinocyte homeostasis and epidermal surveillance and immunity (16-19). Strikingly, Tcrd ${ }^{-/}$mice, which lack $\gamma \delta \mathrm{T}$ cells including DETC, display severe defects in skin wound closure, surveillance of cutaneous Staphylococcus aureus infection, and skin hydration status under challenge conditions (19-21). Importantly, $\gamma \delta \mathrm{T}$ cells exist in both mouse and human epidermis and contribute to the epidermal immune system and wound repair $(22,23)$.

Conflict of interest: The authors have declared that no conflict of interest exists. Citation for this article: J Clin Invest. 2013;123(10):4364-4374. doi:10.1172/JCI70064.
DETC recognize an undefined self antigen expressed by stressed or damaged keratinocytes in a TCR-dependent manner $(24,25)$. Once activated, DETC respond by local secretion of chemokines and cytokines, which in turn regulate skin inflammatory responses $(21,26,27)$. DETC produce a variety of cytokines, which are mostly proinflammatory, but do not fit into a clear Th cell-based scheme of restricted cytokine production, as observed for Th1, Th2, Th17, or Tregs (28). While it is well accepted that DETC are potent IFN- $\gamma-$ producing cells $(26,29)$, their role in IL-17A production remains controversial (30-33). However, epidermal, but not dermal, $\gamma \delta \mathrm{T}$ cells have been shown to produce significant amounts of IL-17A upon cutaneous Staphylococcus aureus infection, whereas dermal, but not epidermal, $\gamma \delta$ T cells produce IL-17A upon Bacillus CalmetteGuerin infection $(20,34)$. These findings indicate that under certain conditions, DETC indeed have the potential to produce IL-17A, although the underlying mechanistic cues are poorly defined.

In this study, we show that a subset of DETC produces IL-17A but not IL-17F or IL-22 upon TCR activation and skin injury and that IL-17A genetic deletion or blocking by neutralizing antibodies results in a delay in skin wound closure. Contrasting previous findings in other $\gamma \delta$ T cells, distinct subsets of IL-17A- and IFN- $\gamma$-producing DETC were identified but did not segregate with expression of CD27 or CD45RB. DETC-derived IL-17A was critical to inducing epidermal murine $\beta$-defensin 3 and S100A8 as well as the regenerating islet-derived (Reg) protein, RegIII $\gamma$. Together, our findings identify DETC as the major source for early epidermal IL-17A production upon skin injury, demonstrate that DETCderived IL-17A is critical for epidermal AMP induction, and show that DETC-derived IL-17A functions to reestablish the antimicrobial skin barrier following injury.

\section{Results}

IL-17A deficiency results in delayed wound healing that can be restored by locally administered recombinant IL-17A. Distinct cytokines play pivotal roles in skin barrier function and wound repair (35-37). 
A
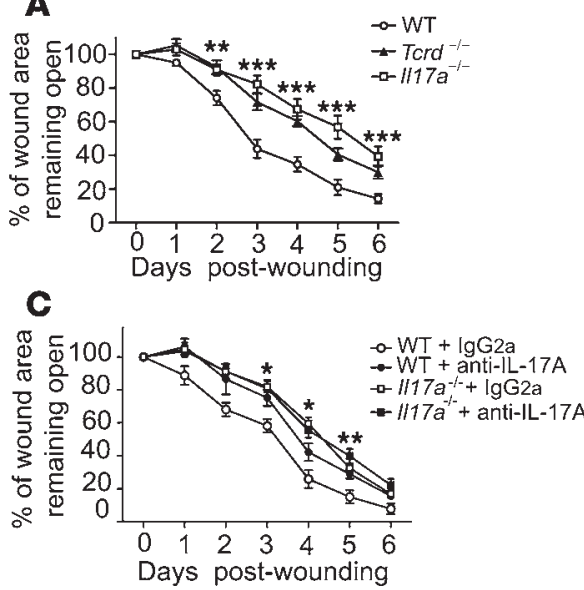

Figure 1

Local IL-17A production is critical for wound healing. (A) $/ 17 \mathrm{a}^{-/-}$mice have delayed wound closure in vivo. Wound-closure kinetics in WT, $\mathrm{Tcrd}^{-1-}$, and $/ 117 \mathrm{a}^{-/-}$mice were measured over time. Data shown represent percentage of wound area remaining open \pm SEM from 4 to 8 wounds. ${ }^{* *} P \leq 0.01 ;{ }^{* *} P \leq 0.001, / 117 a^{-/-}$versus WT. (B) Wound-healing kinetics were measured in SOCs from WT, $\mathrm{TCrd}^{-/-}$, and $/ 117 \mathrm{a}^{-/-}$mice. In some conditions, wounded skin was supplemented with rIL-17A or vehicle control. Data are presented as mean \pm SEM from 3 wounds per condition. ${ }^{*} P \leq 0.05$; ${ }^{* * *} P \leq 0.001$, WT versus $/ 117 a^{-1-}$. (C) Blockade of IL-17A inhibits wound closure in vivo. Neutralizing IL-17 Ab or control Ab ( $\left.\operatorname{lgG}_{2 a}\right)$ was applied into the wound bed of WT and $1 / 17 a^{-/}$mice. Data are presented as the mean percentage of the wound area remaining open \pm SEM from 4 to 8 wounds. ${ }^{\star} P \leq 0.05 ;{ }^{\star \star} P \leq 0.01$. (D) Recombinant IL-17A restores defective wound healing in $1 / 17 a^{-/-}$skin in vivo. Wounded skin was supplemented with rIL-17A or vehicle control, and woundhealing kinetics were measured over time. Data shown represent mean \pm SEM of 4 to 8 wounds per condition. ${ }^{\star} P \leq 0.05 ;{ }^{* \star} P \leq 0.01 ;{ }^{* \star} P \leq 0.001, \| 17 a^{-/-}$versus WT.

IL-17A is readily detectable in human and mouse skin wounds $(9,10)$ and functions in host defense, inflammation, and epithelial cell proliferation $(20,38-40)$. Therefore, we sought to investigate whether deficiency of IL-17A results in changes in cutaneous wound-healing kinetics by measuring and calculating the percentage of wound area remaining open, as previously described by our laboratory and others $(21,29,41)$. In vivo measurements of wound closure revealed that $I l 17 a^{-/-}$mice displayed delayed wound healing compared with WT mice, with very similar kinetics to the delay seen in $\mathrm{Tcrd}^{-/-}$mice (Figure 1A). In line with this observation, keratinocyte proliferation, which is critical for the initiation of wound reepithelialization, was markedly decreased at the wound site of $I l 17 \mathrm{a}^{-/-}$mice compared with WT controls (Supplemental Figure 1A; supplemental material available online with this article; doi:10.1172/JCI70064DS1). To exclude the possibility that DETC in $I l 17 a^{-/-}$mice had intrinsically reduced numbers or proliferation upon activation, resulting in delayed wound-healing responses, we examined homeostatic numbers and proliferative capacities of DETC from WT and $\mathrm{Il}_{\mathrm{H}} \mathrm{a}^{-/-}$mice, but did not observe any significant differences (Supplemental Figure 1B). To rule out the possibility that delayed wound healing in $\mathrm{Il17}^{-/-}$skin was driven by impaired infiltration of immune cells relevant to wound repair, we chose to evaluate the wound-healing response further in the well-established in vitro skin organ culture (SOC) system (21), where peripheral immune cells cannot migrate into the wound bed. Using this in vitro approach, we observed that $I l 17 \mathrm{a}^{-/-}$skin wounds also displayed significant wound-closure defects, with kinetics very similar to that of wounds from $\mathrm{Tcrd}^{-/}$ mice (Figure 1B), similar to the observations made in the in vivo wound-healing system (Figure 1A), suggesting that IL-17A produced by resident skin cells is critical to the woundhealing response. To corroborate the requirement of IL-17A for the cutaneous wound-healing response, IL-17A activity was blocked in vivo by a neutralizing anti-IL-17A antibody. Consistent with our findings that $I l 17 \mathrm{a}^{-/-}$mice showed delayed wound healing, treatment of wounds with anti-IL-17A antibodies administered directly into the wound bed, but not with control $\operatorname{IgG}_{2 \mathrm{a}}$, delayed wound repair in WT, but not in $I l 17 a^{-1-}$ or $\mathrm{Tcrd}^{-/-}$, mice (Figure 1C and data not shown). Together, these findings demonstrate an essential role of IL-17A in wound repair.

Given the critical role of IL-17A for the cutaneous wound-healing response, we next tested whether addition of IL-17A into the wound bed could restore defective wound closure in $I l 17 a^{-/-}$mice. Exogenous recombinant IL-17A was added into the wound bed and was able to rescue the wound-healing defect in $I l 17 \mathrm{a}^{-/-}$skin and restore it to WT levels in vitro and in vivo (Figure 1, B and D, and Supplemental Figure 1E), emphasizing that locally administered recombinant IL-17A alone was sufficient to fully restore defective wound healing in $I l 17 \mathrm{a}^{-/-}$mice. However, administration of recombinant IL-17A to WT wounds did not significantly affect wound healing (Figure 1D). Collectively, results from these in vitro and in vivo wound-healing studies strongly suggested that local IL-17A production plays a crucial and nonredundant role in cutaneous wound healing.

TCR stimulation is required for production of $I L-17 A$ by a subset of DETC. DETC play an essential role in wound repair (21), and therefore, we sought to determine whether DETC are the source of IL-17A in the epidermal compartment. We reasoned that direct TCR ligation would be critical for IL-17A production by DETC, because DETC become activated through their TCR by recognition of self antigens expressed on wounded keratinocytes $(25,42)$. Indeed, we observed that freshly isolated and sorted $\mathrm{V} \gamma 3^{+}$DETC stimulated with anti-CD3 $\varepsilon$ strongly induced $I L-17 \mathrm{~A}$ mRNA and protein (Figure 2, A and B). Proteins for IL-17F and IL-22, however, were not detected in resting or activated DETC (Figure $2 \mathrm{~B}$ and Supplemental Figure 2A). Cyclosporin A (CsA) is known to potently block TCR-mediated T cell activation through inhibition of calcineurin and subsequent nuclear factor of activated T cells (NFAT) activation (43). Strikingly, TCR-mediated IL-17A production was completely inhibited by CsA treatment, suggesting that TCR activation is critical for IL-17A production in DETC (Figure 2C). Stimulation with the master cytokine regulators IL-23 plus IL-1 $\beta$ in the absence of TCR stimulation has been found to induce strong IL-17A production in some $\gamma \delta \mathrm{T}$ cells, but not in DETC (30). In line with these findings, we did not observe IL-17A production in sorted $\mathrm{V} \gamma 3^{+}$DETC upon stimulation with IL-23 plus IL-1 $\beta$ or IL-23 or IL-1 $\beta$ alone (Figure 2D). However IL-23 plus 
A

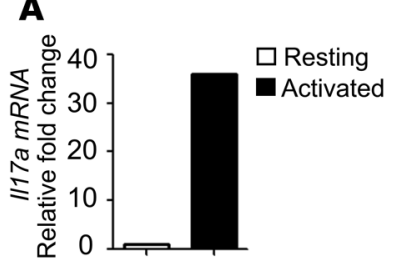

B
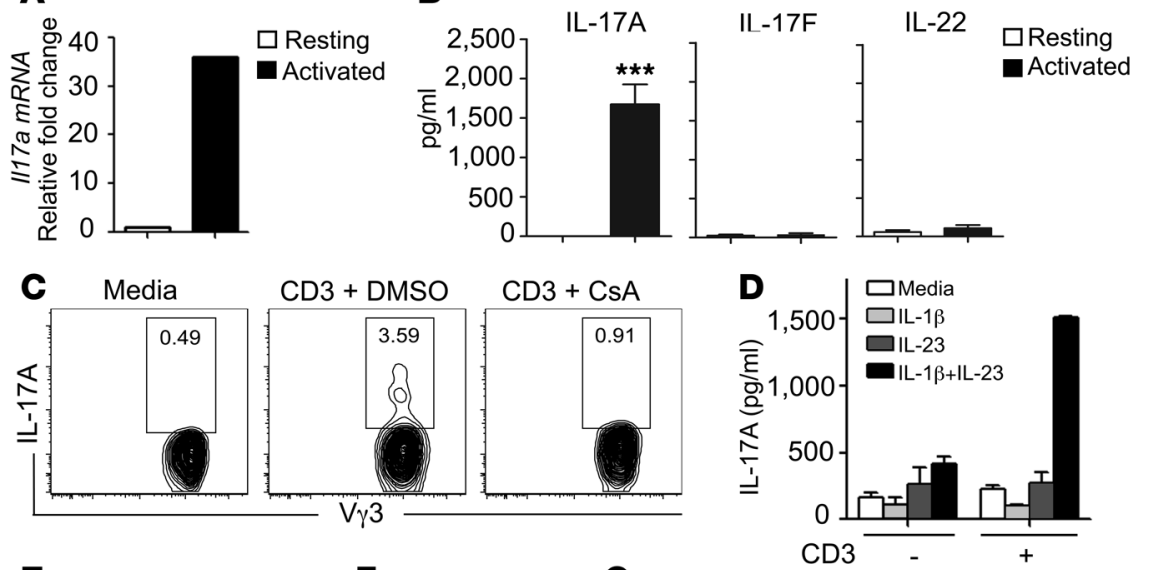

$\mathbf{E}$

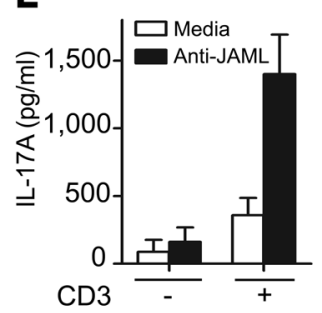

$\mathbf{F}$

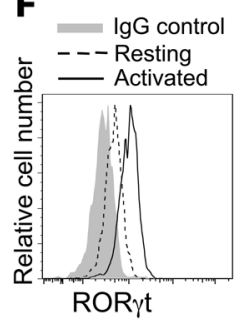

G

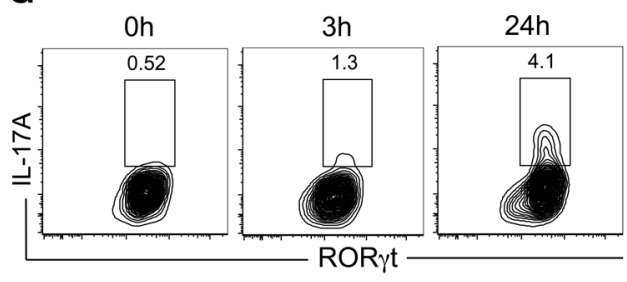

Figure 2

IL-17A production by a subset of DETC requires TCR stimulation. (A) DETC upregulate I/17a upon TCR stimulation in vitro. Sorted $\mathrm{V} \gamma 3^{+}$DETC express $/ / 17$ a following activation by plate-bound anti-CD3 $\varepsilon$ $(10 \mu \mathrm{g} / \mathrm{ml})$. (B) Freshly isolated and sorted $\mathrm{V} \gamma 3^{+}$DETC were stimulated with plate-bound anti-CD3 $\varepsilon$ $(10 \mu \mathrm{g} / \mathrm{ml})$, and IL-17A, IL-17F, and IL-22 protein was measured by ELISA. Data are shown as mean \pm SEM from quadruplicate measurements and are representative of 3-4 independent experiments. ${ }^{* * *} P \leq 0.001$. (C) CsA inhibits anti-CD3 $\varepsilon-$ mediated IL-17A production in DETC. Cells are gated on $\mathrm{V} \gamma 3^{+}$Thy $1.2^{+}$. (D) Stimulation with IL-1 $\beta$ and IL-23 alone does not induce IL-17A in DETC. Sorted V $\gamma 3^{+}$ DETC were stimulated with IL-1 $\beta, I L-23$, or the combination thereof in the presence or absence of suboptimal anti-CD3 $\varepsilon$, and IL-17A secretion was assayed by ELISA. Data are shown as mean \pm SEM from duplicates. (E) JAML costimulation increases IL-17A in DETC. ELISA analysis for IL-17A from culture supernatants of DETC stimulated with antibody against suboptimal doses of CD3 alone, CD3 and JAML, or JAML alone. Data are shown as mean \pm SEM from duplicates. (F) DETC upregulate

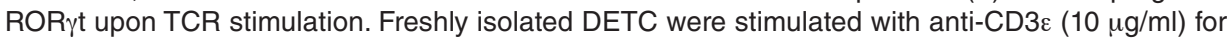
3 hours, and ROR $\gamma$ t levels were measured by flow cytometry. (G) A subset of ROR $\gamma \mathrm{t}^{+}$DETC produces IL-17A. ROR $\gamma$ t and IL-17A expression were assessed by flow cytometry in freshly isolated epidermal cell suspensions that were stimulated with anti-CD3 $\varepsilon(10 \mu \mathrm{g} / \mathrm{ml})$. Cells are gated on $\mathrm{V} 3^{+}$Thy $1.2^{+}$.

IL-1 $\beta$ enhanced TCR-mediated IL-17A production when a suboptimal amount of anti-CD3 $\varepsilon$ was used for stimulation (Figure 2D). IL-17A production induced by high-dose anti-CD3e, in contrast, could not be further enhanced by IL-23 plus IL-1 $\beta$ (data not shown). Based on the recent discovery of the junctional adhesion moleculelike protein (JAML) as a critical costimulatory molecule for TCRmediated DETC activation (29), we reasoned that JAML costimulation may play a role in IL-17A production as well. Stimulation of DETC with crosslinked anti-JAML antibodies augmented TCRmediated IL-17A production (Figure 2E). Furthermore, following stimulation with low-dose $(1 \mu \mathrm{g} / \mathrm{ml})$ or high-dose $(10 \mu \mathrm{g} / \mathrm{ml})$ anti-CD3e, different secretion kinetics were observed for IL-17A, TNF- $\alpha$, and IFN- $\gamma$ (Supplemental Figure 2B). Upon stimulation with low-dose anti-CD3E, IL-17A was detected in culture supernatants earlier than TNF- $\alpha$ and IFN- $\gamma$, whereas high-dose TCR stimulation resulted in similar secretion kinetics between IL-17A, TNF- $\alpha$, and IFN- $\gamma$ (Supplemental Figure 2B). These results demonstrate that IL-17A is rapidly secreted following TCR stimuladespite upregulation of ROR $\gamma \mathrm{t}$ in DETC upon activation, only a subset of TCR-stimulated ROR $\gamma \mathrm{t}^{+} \mathrm{DETC}$ was able to produce large amounts of IL-17A, suggesting that induction of ROR $\gamma t$ alone is not sufficient to mediate IL-17A production in DETC. Similarly, IFN- $\gamma$-producing DETC were characterized by their expression of T box transcription factor (T-bet); however, only a subset of T-bet ${ }^{+}$ DETC produced IFN- $\gamma$ (Supplemental Figure 2E), suggesting that T-bet alone was not sufficient for IFN- $\gamma$ induction in DETC.

A subset of DETC produces IL-17A upon skin injury in a V $\gamma 3$-dependent manner. Next, we assessed the ability of DETC to produce IL-17A in response to in vivo skin wounding. Intracellular cytokine staining performed demonstrated that only DETC isolated from the epidermis surrounding the wound site, but not from nonwounded skin, contained a subset of IL-17A-producing cells (Figure 3A). These findings were corroborated by quantitative PCR (qPCR) analyses of Il17a using sorted DETC from nonwounded and wounded areas (Figure 3B). ROR $\gamma t$ levels were increased in DETC isolated from skin directly surrounding the wound site compared with 

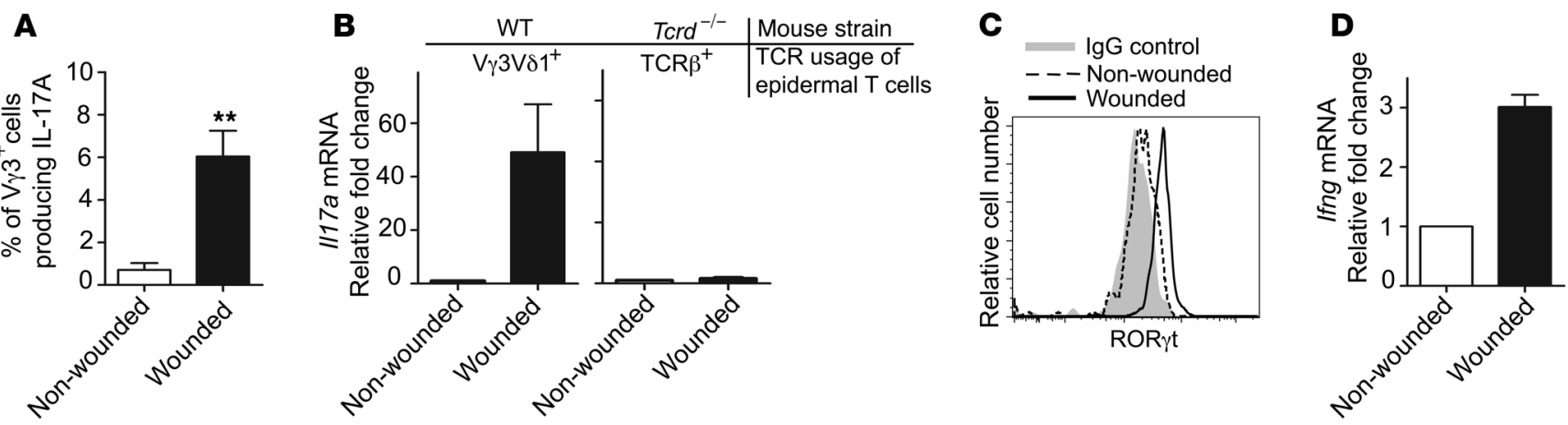

Figure 3

DETC produce IL-17A upon skin injury in vivo. (A) Increased frequency of IL-17A-producing $\mathrm{V} \gamma 3^{+} \mathrm{DETC}$ in wounded skin. Epidermal cells were isolated from skin areas directly surrounding wounds or from nonwounded skin, 18 hours after wounding. Intracellular IL-17A production was analyzed by flow cytometry. Data are pooled and shown as the mean \pm SEM of $\mathrm{V} \gamma 3$ cells producing IL-17A from independent analyses of 4 mice and are expressed as percentage of $\mathrm{V} \gamma 3^{+}$cells producing IL-17A. ${ }^{*} P<0.01$. (B) Signaling through the $\mathrm{V} \gamma 3 \mathrm{~V} \delta 1 \mathrm{TCR}$ is required for DETC-mediated IL-17A expression in vivo. V $\gamma 3^{+}$DETC from WT and epidermal TCR $\beta^{+}$cells from $\mathrm{Tcrd}^{-/-}$mice were isolated and sorted from the epidermis of wounded and nonwounded skin areas 18 hours following skin injury. IL-17A was measured by qPCR. Data are pooled and shown as mean \pm SEM from 3 independent experiments with at least 4 mice per genotype per experiment. (C) ROR $\gamma t$ increases in DETC upon skin injury. DETC were isolated 12 hours following skin injury from nonwounded and wounded skin areas and were stained for ROR $\gamma$ t. Cells are gated on $\mathrm{V} \gamma 3^{+}$Thy $1.2^{+}$. (D) Ifng is upregulated upon skin injury. $\mathrm{V} \gamma 3^{+} \mathrm{DETC}$ were isolated and sorted from the epidermis of wounded and nonwounded skin areas 18 hours following skin injury. Ifng was measured by qPCR. Data are pooled and shown as mean \pm SEM from 3 independent experiments with at least 4 mice per genotype per experiment.

those from nonwounded skin (Figure 3C). In addition to Il17a, Ifng was also upregulated in DETC upon wounding (Figure 3D), an observation made previously by our laboratory (21), albeit to a lesser extent than $I l 17 a$ expression at 18 hours after wounding.

$\mathrm{Tcrd}^{-/-}$mice lack V $\gamma 3 \mathrm{~V} \delta 1$ DETC in the skin, but harbor a population of $\alpha \beta$ TCR-bearing cells in the epidermis (24). These TCR $\beta^{+}$ cells have a polyclonal $\mathrm{V} \beta$ repertoire and, importantly, do not recognize the uncharacterized DETC antigen expressed by keratinocytes (24). To determine whether this $\alpha \beta$ T cell population in the $\mathrm{Tcrd}^{-/-}$epidermis responds to skin wounding with upregulation of Il17a, similar to what we observed in WT DETC, sorted epidermal $\mathrm{T}$ cells from $\mathrm{Tcrd}^{-/}$mice were analyzed. We found that, in contrast to $\mathrm{V} \gamma 3^{+}$DETC isolated from wounded WT skin, these surrogate epidermal $\alpha \beta$ T cells from Tcrd ${ }^{-/}$skin, although expressing IL-17A transcript constitutively, failed to upregulate Il17a mRNA upon wounding (Figure 3B). This suggests that functional V $\gamma 3 \mathrm{~V} \delta 1$ TCR signaling is necessary for optimal induction of IL-17A in DETC upon wounding. Alternatively, dysregulated $\alpha \beta \mathrm{T}$ cells or keratinocytes in $\mathrm{Tcrd}^{-/}$skin may contribute to the defective response to skin injury $(17,51)$.

IL-17A- and IFN- $\gamma$-producing DETC subsets maintain their CD27$C D 45 R B^{+}$phenotype. A number of characteristic phenotypic markers have been recently described to identify thymic DETC precursors and other $\gamma \delta \mathrm{T}$ cell subsets based on their maturation, memory phenotype, and cytokine commitment $(31,34,52)$. Importantly, CD27 has been proposed as a critical molecule to distinguish between IL-17A-

\section{Figure 4}

IL-17A- and IFN- $\gamma$-producing DETC subsets maintain their $\mathrm{CD}_{27}-45 \mathrm{RB}^{+}$phenotype. (A) Phenotypic characterization of freshly isolated WT and $/ 117 a^{-/-}$DETC. Cells are gated on $\mathrm{V} \gamma 3^{+}$Thy $1.2^{+}$and CD45RB, CD27, NK1.1, CD62L, CD122, IL-7R, and CD69 expression (solid lines), and their appropriate IgG controls (gray) were measured by flow cytometry. (B) Distinct DETC subsets produce IL-17A and IFN- $\gamma$. Intracellular staining on DETC short-term cell lines stimulated with antiCD3 $\varepsilon(10 \mu \mathrm{g} / \mathrm{ml})$ for IL-17A and IFN- $\gamma$ production. Cells are gated on $\mathrm{V} \gamma 3^{+}$Thy $1.2^{+}$. (C) IL-17A- and IFN- $\gamma$-producing DETC are CD27-CD45RB+. Fresh epidermal cell suspensions were stimulated with anti-CD3ع $(10 \mu \mathrm{g} / \mathrm{ml})$, and expression of CD27, CD45RB, and intracellular IL-17A and IFN- $\gamma$ were measured by flow cytometry. Cells are gated on IL-17A ${ }^{+} \mathrm{V} \gamma 3^{+}$Thy $1.2^{+}$ and IFN- $\gamma^{+} \vee \gamma 3^{+}$Thy $1.2^{+}$, respectively.

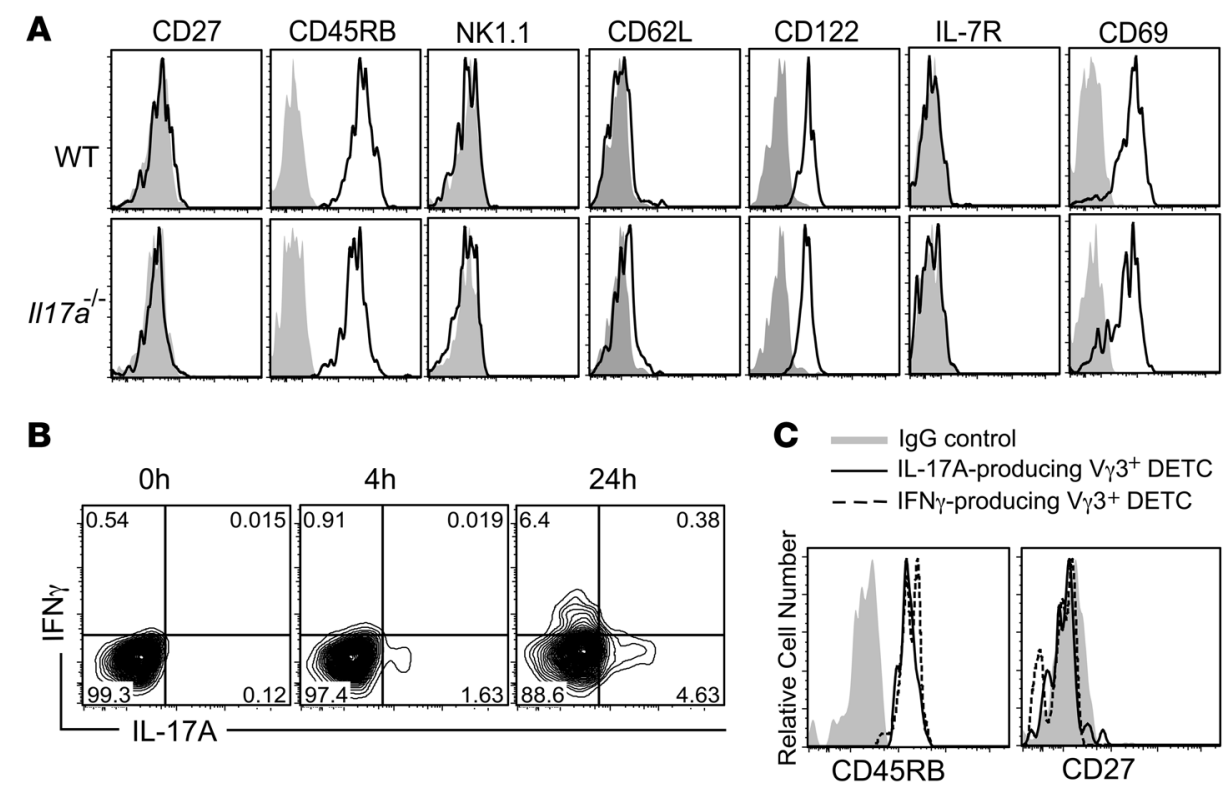



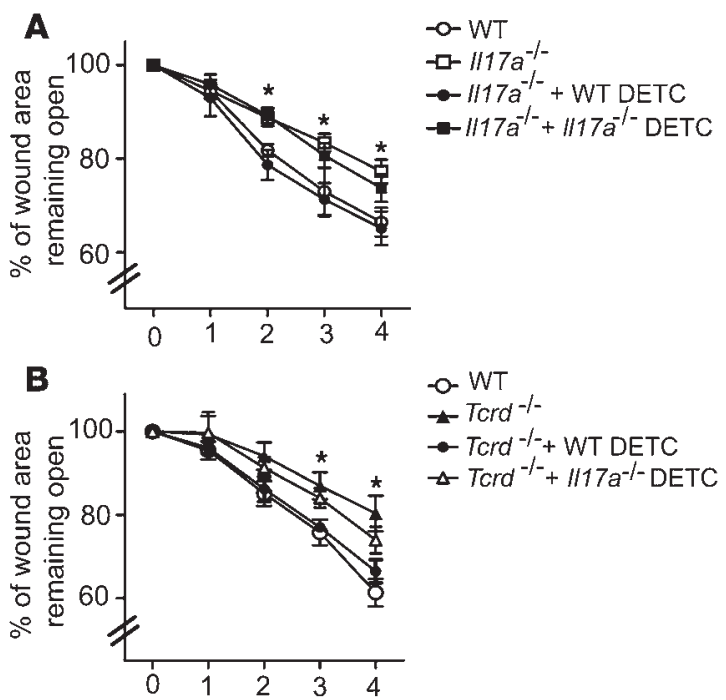

Figure 5

WT but not $/ 17 a^{-/-}$DETC restore defective wound healing. Preactivated WT or $1 / 17 a^{-1}$ DETC were added into the wound bed of wounded skin explants from $/ 17 \mathrm{a}^{-/-}(\mathrm{A})$ or $\mathrm{Tcrd}^{-1-}$ (B) mice, and wound-healing kinetics in SOC were measured over time. Data presented are mean \pm SEM from 3 wounds per condition. ${ }^{*} P<0.05, / 117 a^{-/}+$WT DETC vs. $/ 17 a^{-/}$ (A) and $\mathrm{TCrd}^{-/-}+$WT DETC vs. Tcrd ${ }^{-/-}$(B).

and IFN- $\gamma$-producing $\gamma \delta \mathrm{T}$ cells, with IL-17A-producing $\gamma \delta \mathrm{T}$ cells being CD27- and IFN- $\gamma$ producers being $\mathrm{CD}^{-1} 7^{+}(52,53)$. We demonstrate that DETC can produce both IL-17A and IFN- $\gamma$ (Figures 2 and 3 and Supplemental Figure 2). However, unlike what has been published for peripheral $\gamma \delta \mathrm{T}$ cells and thymic DETC precursors $(52,53)$, CD27 expression was absent on all DETC (Figure 4A), in line with a previous report by Cai et al. (30). In addition, all DETC were found to be CD45RB ${ }^{+} \mathrm{NK} 1.1^{-} \mathrm{CD} 62 \mathrm{~L}^{-} \mathrm{CD} 122^{+} \mathrm{IL}^{-7 \mathrm{R}^{-} \mathrm{CD} 69^{+}}$ (Figure 4A), whereas CD27, CD62L, IL-7R, and NK1.1 were detected on splenocytes used as positive controls (Supplemental Figure 3 , A and B). The DETC surface marker profile identified here corresponds to an "intermediate" phenotype of what has been described to distinguish IL-17A- and IFN- $\gamma$-producing fetal thymic DETC precursors, with IL-17A producers being CD45RB-CD27-NK1.1IL-7R ${ }^{+}$and IFN- $\gamma$ producers being $\mathrm{CD}^{2} 5 \mathrm{RB}^{+} \mathrm{CD} 27^{+} \mathrm{NK} 1.1^{+} \mathrm{IL}-7 \mathrm{R}^{-}$ (52). As expected, WT and $I l 17 a^{-1-}$ DETC had indistinguishable surface-marker expression profiles, suggesting that lack of IL-17A per se does not affect the DETC phenotype (Figure 4A).

As DETC could not be separated into potential IL-17A or IFN- $\gamma$ producers based on their phenotype, we next investigated whether IL-17A- and IFN- $\gamma$-producing DETC were distinct cell subsets, as has been shown for other $\gamma \delta \mathrm{T}$ cells (53), or double producers. IL-17A and IFN- $\gamma$ production were analyzed by intracellular FACS staining 4 and 24 hours following continuous TCR stimulation. IL-17A but not IFN- $\gamma$ was detected in a subset of DETC as early as 4 hours after stimulation, whereas IFN- $\gamma$ and IL-17A were detectable in distinct subsets of DETC following 24 hours of stimulation (Figure 4B). Interestingly, both IFN- $\gamma$ - and IL-17A-producing DETC subsets retained their $\mathrm{CD}^{2} 7^{-} \mathrm{CD} 45 \mathrm{RB}^{+}$phenotype following activation (Figure 4C), demonstrating that IL-17A- and IFN- $\gamma$ producing DETC are distinct subsets, but they cannot be distinguished on the basis of CD27 and CD45RB expression, unlike thymic DETC precursors or other $\gamma \delta$ T cells (52-54).
IL-17A produced by DETC is sufficient to improve defective wound healing in Il17 $a^{-/}$and Tcrd $/ /$mice. To determine whether DETC-derived IL-17A is sufficient to mediate the wound-healing response, wounds from $I l 17 a^{-/}$mice were supplemented in SOC with physiological numbers of WT or Ill17 $a^{-/}$DETC. Addition of WT DETC to wounded $I l 17 a^{-1}$ SOCs restored wound healing to WT levels, whereas $I l 17 a^{-/}$DETC only partially aided wound healing (Figure 5A). Consistent with previous results from our laboratory $(16,21)$, WT DETC added to $\mathrm{Tcrd}^{-1-}$ SOC significantly enhanced wound closure (Figure 5B). In contrast, Il17a $a^{-/}$DETC only partially restored wound healing, suggesting that $I l 17 a^{-/}$DETC can provide some components to aid the wound-healing response; however, their lack of IL-17A precludes them from fully restoring wound healing. Collectively, these results demonstrate that DETC-derived IL-17A exerts a previously unrecognized role in cutaneous wound healing.

IL-17A induces epidermal host-defense molecules upon skin barrier disruption to aid the wound-healing response. Coinciding with the production of IL-17A by DETC upon in vivo wounding (Figure 3, A and B), we observed upregulation of the IL-17 receptor A (IL-17RA) on wounded keratinocytes (Figure 6A), suggesting that keratinocytes are a likely target of IL-17A signaling upon skin injury. Since IL-17A regulates distinct AMP production in epithelial cells and tissues $(50,55)$, this prompted us to investigate the effect of IL-17A on AMP expression in primary murine keratinocytes (Figure 6B). Keratinocytes were stimulated with recombinant IL-17A, and AMP expression was assayed by qPCR over time. We detected a significant increase in mRNA expression of Defb3 and S100a8, while expression levels of Defb1 and Defb2 were not significantly changed upon IL-17A stimulation (Figure 6B). AMP function to regulate multiple immune responses relevant to wound healing (11-13, 56-59). Indeed, in vivo skin injury strongly induced epidermal Defb3, S100a8, and the novel cutaneous AMP, Reg3g, expression in WT mice in line with previous reports $(14,58-60)$, and we found here that IL-17A deficiency or a lack of $\gamma \delta$ T cells severely compromised this induction (Figure 6C). In addition, increased $\beta$-defensin 3 and RegIII $\gamma$ protein staining was observed in the epidermis of WT wounds, whereas induction of these AMP was reduced in $I l 17 a^{-/-}$or $\mathrm{Tcrd}^{-/}$skin (Figure 6D). Induction of epidermal S100A8 was also decreased in $I l 17 a^{-/}$mice compared with WT mice (Figure 6D). Thus, we demonstrate that IL-17A and $\gamma \delta$ T cells are critical for epidermal AMP induction following wounding.

Recently, a functional role for RegIII $\gamma$ has been shown in the cutaneous wound-healing response (59). To directly assess whether $\beta$-defensin 3 and S100A8 also affect the wound-healing response, excisional wounds of WT and $I l 17 a^{-/-}$mice were treated in vivo with recombinant $\beta$-defensin 3 or S100A8 and wound-healing kinetics were measured (Figure 6E and Supplemental Figure 4). $\beta$-Defensin 3 but not S100A8 restored defective wound healing in $I l 17 a^{-/}$mice compared with vehicle controls; however, no accelerated wound closure was observed in WT mice (Figure 6E, Supplemental Figure 4, and data not shown). Thus, in addition to the recently established role of RegIII $\gamma$ (59), we here identified a functional role of $\beta$-defensin 3 in the wound-healing response. The importance of DETC-derived IL-17A for epidermal AMP induction is further supported by the finding that addition of WT DETC to wounded skin from $I l 17 a^{-/-}$mice in SOC upregulated epidermal $\beta$-defensin 3 and RegIII $\gamma$ (Figure 7 and Supplemental Figure 5). In contrast, addition of neutralizing anti-IL-17A antibodies to WT DETC and the SOC (Figure 7) or supplementation of SOC with DETC deficient in IL-17A (Supplemental Figure 5) impaired the 
A

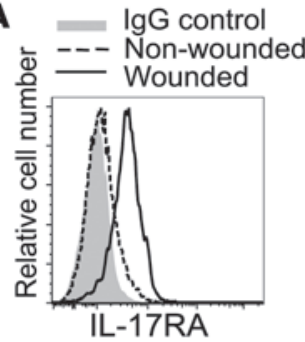

C
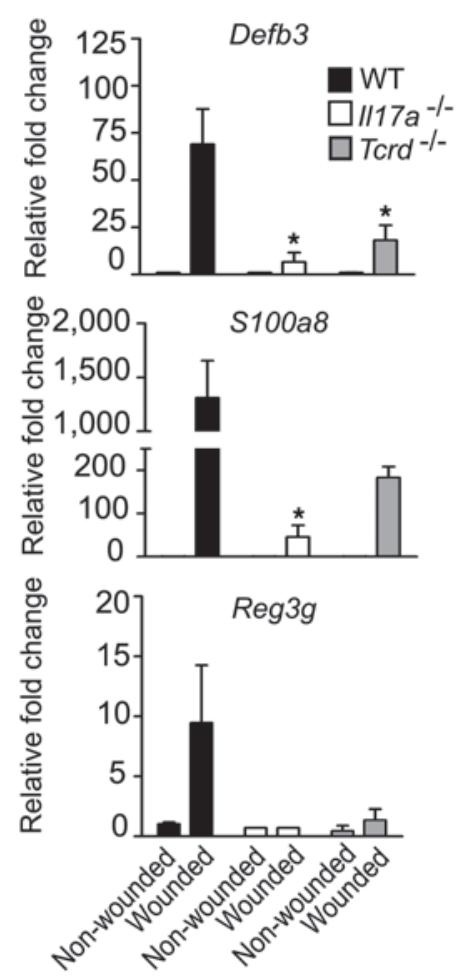

D
B

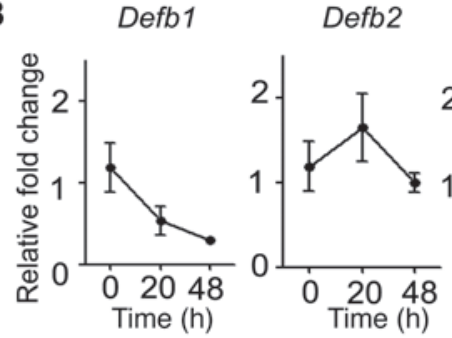

Defb3

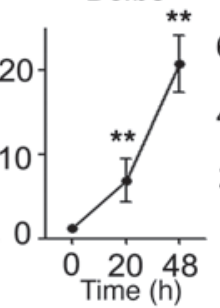

S100a8

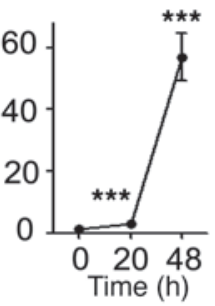

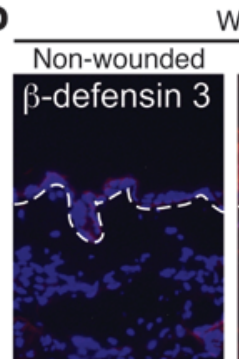

WT

Wounded
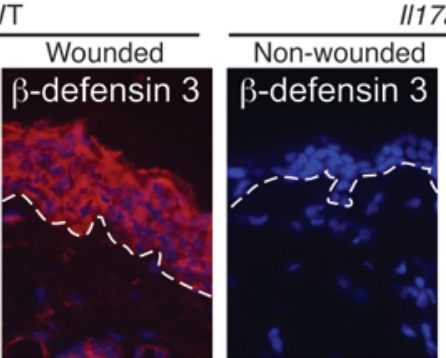

Wounded
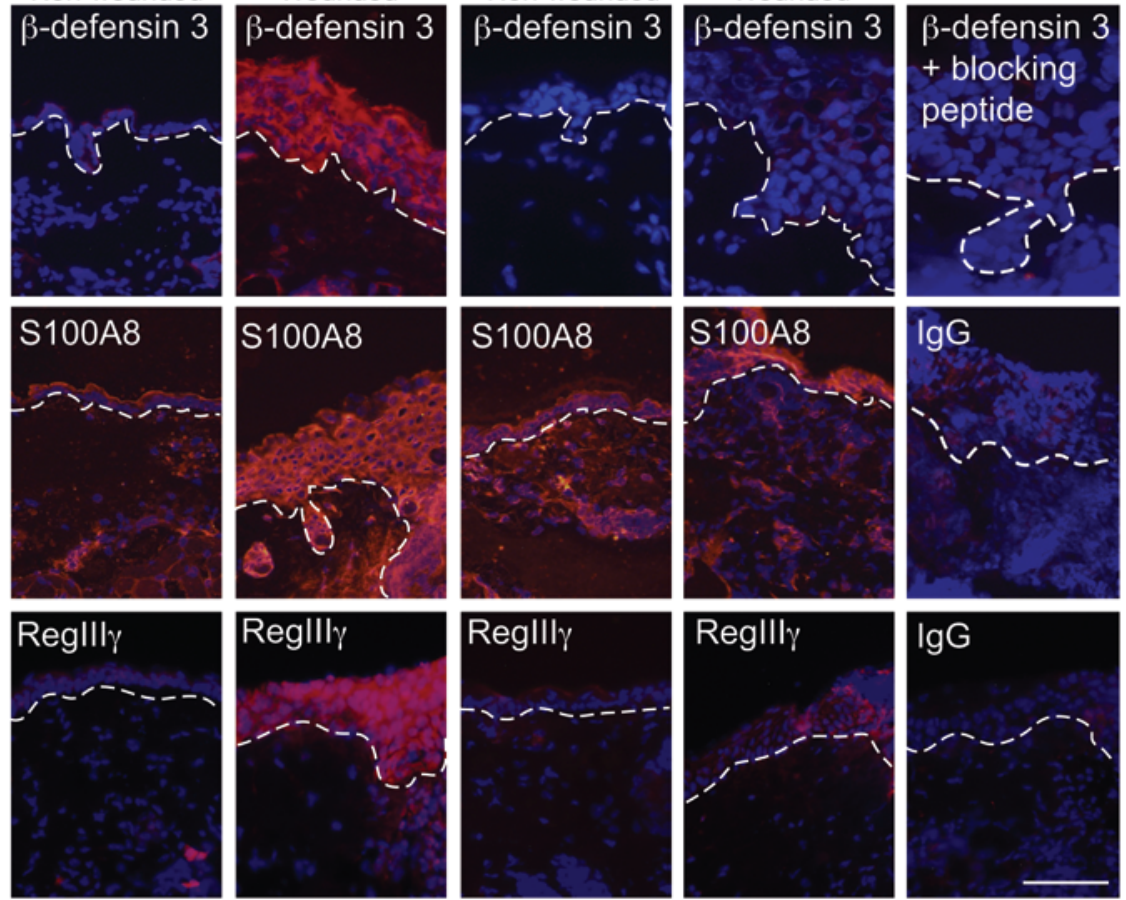

E

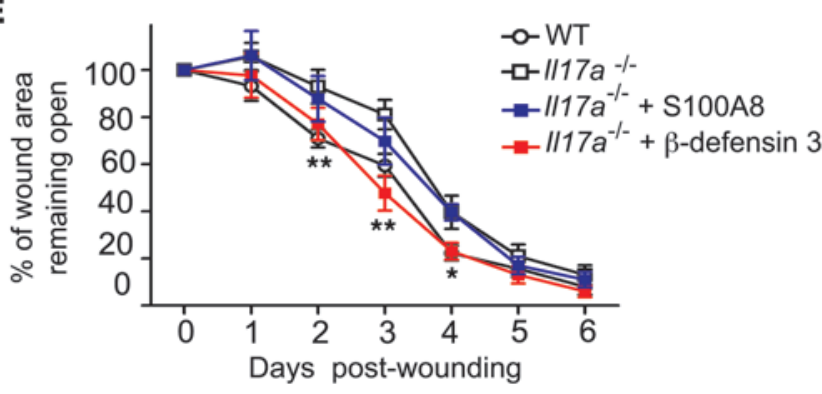

Figure 6

IL-17A is critical for induction of epidermal host-defense molecules to mediate wound repair. (A) IL-17RA expression increases upon wounding. Epidermal cells isolated from nonwounded and wounded sites were stained for IL-17RA 18 hours following wounding. Cells are gated on CD45-. (B) IL-17A induces murine Defb3 and S100a8 in primary murine keratinocytes. ${ }^{\star \star} P<0.01 ;{ }^{* \star \star} P<0.001$. (C and D) Induction of AMP upon wounding is impaired in $1 / 17 a^{-/-}$mice. Levels of epidermal $\beta$-defensin $3, \mathrm{~S} 100 \mathrm{~A} 8$, and Reglll $\gamma$ were analyzed (C) by qPCR of epidermal sheets from nonwounded and wounded skin or (D) by immunofluorescence staining of wounded and nonwounded skin from WT and I/17a ${ }^{-/-}$animals 24 hours after wounding. (C) For qPCR, data are pooled from 4-6 wounds and expressed as mean \pm SEM from 3 independent experiments. Data are expressed as relative fold change compared with nonwounded controls. ${ }^{*} P \leq 0.05$. (D) Antibodies recognizing $\beta$-defensin 3 , S100A8, or Reglll $\gamma$ were used (red staining). DAPI was used to visualize cell nuclei (blue staining). Dotted white lines represent the epidermal-dermal border. Scale bar: $50 \mu \mathrm{m}$. (E) $\beta$-Defensin 3 but not S100A8 ameliorates defective wound healing in $/ 117 a^{-/-}$mice in vivo. Skin wounds were treated with recombinant $\beta$-defensin 3 or S100A8, and wound-healing kinetics were measured over time. Data shown represent mean \pm SEM of 4 to 8 wounds per condition. ${ }^{*} P \leq 0.05 ;{ }^{* *} P \leq 0.01, / 117 a^{-/}$versus $/ / 17 a^{-/}+\beta$-defensin 3 . 


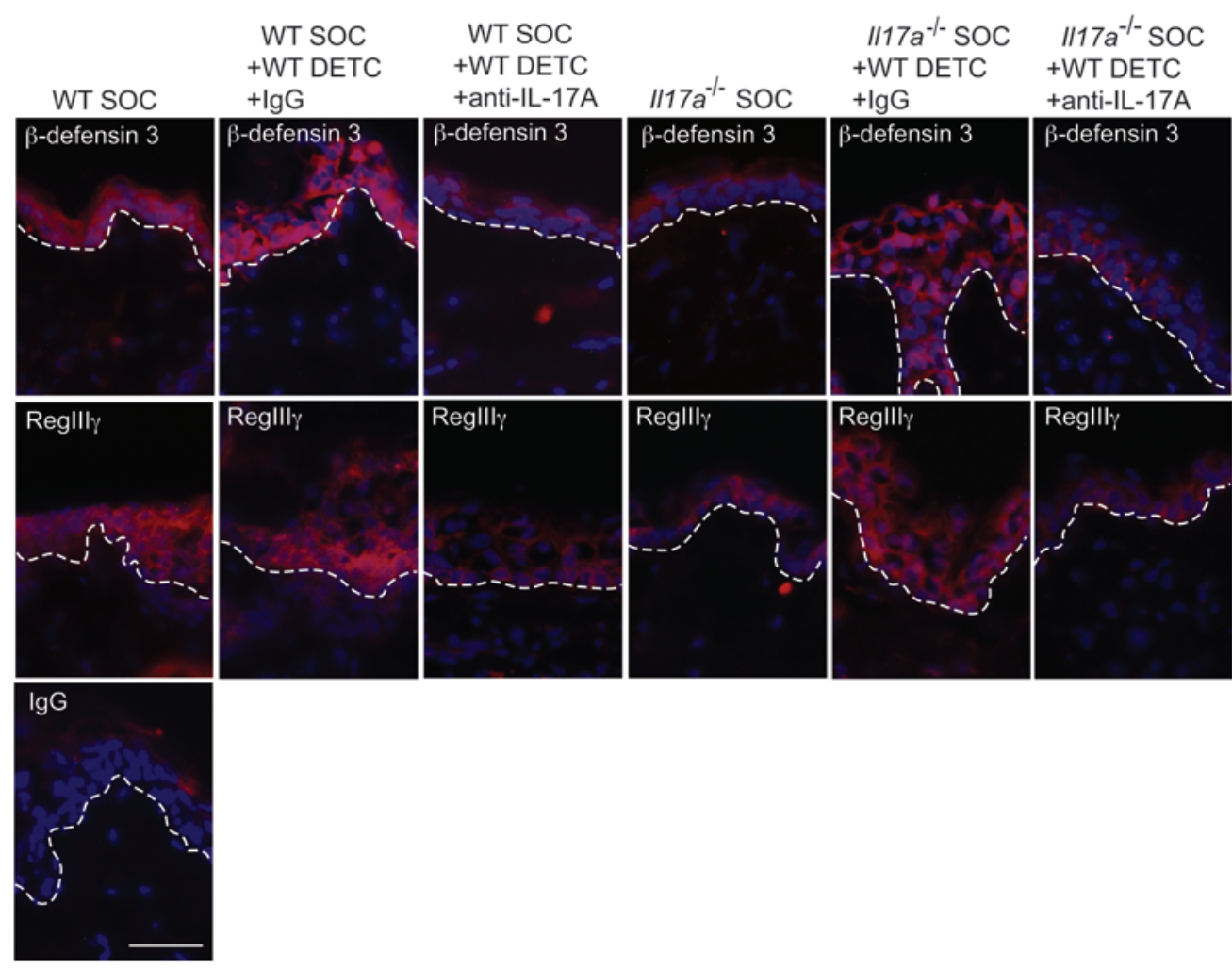

\section{Figure 7}

Robust restoration of antimicrobial peptides in $1 / 17 a^{-/-}$skin wounds by WT DETC via an IL-17A-dependent mechanism. Wounded SOCs from WT or $1 / 17 a^{-/-}$mice were supplemented with preactivated WT DETC. Neutralizing anti-IL-17A antibody together with preactivated DETC was added into the wound bed of SOCs. Skin directly adjacent to the wound bed was analyzed for $\beta$-defensin 3 and Reglll $\gamma$ expression (red staining). DAPI was used to visualize cell nuclei (blue staining). Dotted white lines represent the epidermal-dermal border. Scale bar: $50 \mu \mathrm{m}$. capacity of DETC to upregulate $\beta$-defensin 3 and RegIII $\gamma$. Collectively, these results demonstrate that DETC-derived IL-17A is critical to inducing epidermal host-defense molecules and functions to promote the wound-healing response.

\section{Discussion}

Wound repair is a complex process involving numerous cell types to accomplish the 3 phases of wound healing, called the inflammatory, proliferation, and tissue-remodeling phases. We and others have shown that IL-17A levels increase from hours to 1 day following acute skin injury prior to the influx of peripheral T cells into the skin in humans and mice $(5,10,37,61)$. Whether DETC are capable of producing IL-17A has been somewhat controversial based on previously published conflicting data $(20,30,31)$. In this study, we identify DETC as the source of epidermal IL-17A upon skin injury, and we show a direct functional role of IL-17Aproducing DETC in regulating epidermal AMP responses to promote wound repair (Figure 8).

Deficiency or blocking of IL-17A resulted in delayed wound closure in vivo. Wound-healing defects in $\mathrm{Il17}^{-/-}$animals could be restored by the addition of recombinant IL-17A or by IL-17A-sufficient WT DETC, but only partially by $I l 17 a^{-/-}$DETC or WT DETC treated with neutralizing anti-IL-17A antibodies in a SOC system. These findings suggest an essential role for DETC-derived IL-17A in the wound-healing response and a previously unrecognized role for DETC to provide IL-17 to promote wound healing.

In contrast to innate-like IL-17-committed peripheral $\gamma \delta \mathrm{T}$ cells, DETC do not respond to cytokine stimulation by production of IL-17A $(30,31)$. Instead, TCR-mediated activation is pivotal to DETC function $(42,62)$, and we demonstrate that TCR-mediated signals are essential for optimal IL-17A production by DETC in vitro and in vivo in response to wounding (Figure 8). Thus, our findings provide a rational explanation as to why recent studies have reported that DETC are unable to produce IL-17A $(30,31)$. Furthermore, PMA plus ionomycin has been found to be largely ineffective in mediating activation-induced DETC proliferation (63), and therefore, it is not surprising that neither IL-17A nor IFN- $\gamma$ production was observed when using this route of stimulation $(30,31)$. Clearly, the presence of costimulatory molecules and cytokine receptors may modulate TCR-mediated DETC activation, even in the presence of only weak TCR stimulation, thus reducing the "TCR threshold" required for initiation of the signaling cascade. This hypothesis is supported by our findings that JAML costimulation or IL-23 plus IL- $1 \beta$ increased IL-17A secretion when suboptimal TCR signaling is used. The binding partner for JAML, coxsackie and adenovirus receptor (CAR), as well as IL-1 $\beta$ and IL-23p19 are upregulated during the wound-healing response $(10,29)$, suggesting that costimulation through JAML or distinct cytokine receptors may have the potential to enhance TCR-mediated IL-17A production by DETC in vivo as the woundhealing response progresses.

Peripheral $\gamma \delta$ T cells and thymic DETC precursors segregate into IL-17A-and IFN- $\gamma$-producing subsets based on their expression of CD27 (52, 53). In line with a previous report (30), we found that mature DETC lack CD27 expression; however, we show that distinct subsets of activated DETC produce IL-17A or IFN- $\gamma$ while maintaining their $\mathrm{CD}_{27}{ }^{-} \mathrm{CD} 45 \mathrm{RB}^{+}$phenotype. This important observation suggests that effector functions are differently regulated in mature DETC compared with DETC precursors and other $\gamma \delta$ $\mathrm{T}$ cells and cannot be segregated on the basis of CD27 expression. While engagement of fetal thymic DETC precursors with Skint1 induces signals relevant for DETC development and maturation, 


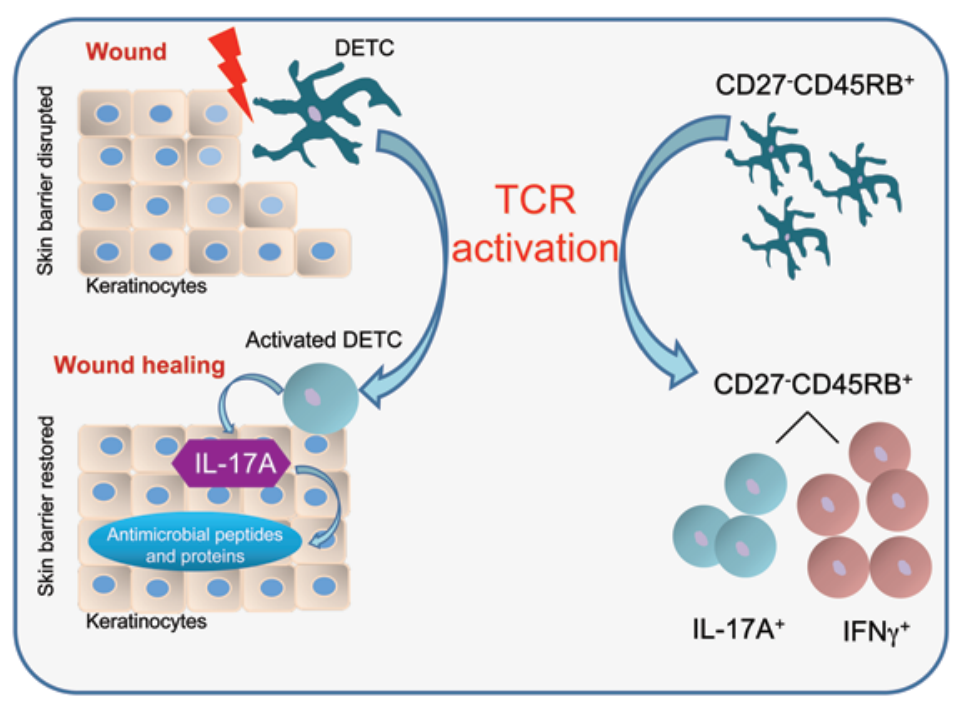

\section{Figure 8}

Schematic model for DETC-regulated immune functions during wound healing. Upon skin injury, DETC become activated and a subset of DETC produces IL-17A. IL-17A is critical to inducing several AMP in keratinocytes, thus helping to reestablish the skin barrier during wound healing. DETCmediated IL-17A production is highly dependent on TCR stimulation. DETC activation via TCR mediates production of IL-17A and IFN- $\gamma$ in distinct subsets despite a homogenous CD27-CD45RB ${ }^{+}$phenotype. This is in contrast with previous observations in peripheral $\gamma \delta$ T cells and thymic DETC precursors, suggesting that DETC cytokine commitment is uniquely regulated. including expression of CD27 and IFN- $\gamma(52,64)$, it appears that cytokine fates of mature DETC are not preprogrammed by this event. Identification of the DETC-TCR ligand will help to investigate whether TCR signaling by DETC precursors in the fetal thymus with ligand(s) directs mature DETC function similar to what has been shown for other $\gamma \delta \mathrm{T}$ cells (65). Alternatively, induction of activation signals of different strengths may determine cytokine fates in the periphery (66-68). The strength of activation is dictated by the antigen dose, the duration of TCR signaling, TCR numbers and occupancy, TCR affinity, and coreceptor signals. Skin injury causes rapid disruption of steady-state $\mathrm{V} \gamma 3 \mathrm{~V} \delta 1 \mathrm{TCR}$ signaling in DETC, followed by the emergence of spatially reorganized activation clusters $(69,70)$. Thus, our observations together with results from previous studies suggest that TCR strength may determine cytokine fates in DETC, as IL-17A, IFN- $\gamma$, and TNF- $\alpha$ are induced in DETC upon different TCR doses in vitro and upon wounding in vivo $(21,29,71)$. Upregulation of TCR ligand(s), ligands for costimulatory molecules, and cytokines following wounding $(29,42)$ may lead to changes in the potency of activation signals, resulting in distinct IL-17A- and IFN- $\gamma$-producing subsets within the DETC pool.

IL-17A signaling is mediated through IL-17RA and IL-17RC (72,73). We here show that keratinocytes upregulate IL-17RA upon skin injury and thus become a likely target for IL-17A signaling. Keratinocytes are a rich source of epidermal AMP, which make up a fundamental component of the innate immune system to protect the host from infections in situations where the physical skin barrier is compromised (74). IL-17A produced by DETC subsequently induced epidermal $\beta$-defensin 3, S100A8, and RegIII $\gamma$ production, which have been shown to function through regulation of keratinocyte migration, energy metabolism, cytoskeletal dynamics, and keratinocyte proliferation and differentiation $(59,60,75,76)$. Induction of AMP was observed as early as 24 hours after wounding, subsequent to IL-17A production by DETC at 18 hours after wounding. AMP induction was most pronounced in the epidermal layer of the skin, and thus it is unlikely that dermal $\gamma \delta \mathrm{T}$ cells, which have recently been described to produce IL-17A as well $(30,31)$, facilitate the epidermal AMP response.

Functionally, in our model system, $\beta$-defensin 3 but not S100A8 restored wound healing in $I l 17 \mathrm{a}^{-/-}$mice. Nonetheless, S100A8 may still play relevant roles during the wound-healing response and may require other IL-17-driven factors for its full function. Expanding previous observations on RegIII $\gamma$ (59), we show here that its upregulation is severely compromised not only in $\mathrm{Ill}_{17 \mathrm{a}^{-/-}}$ but also in $\mathrm{Tcrd}^{-1-}$ mice. Furthermore, WT DETC could restore RegIII $\gamma$ expression in $I l 17 a^{-/-}$wounds, suggesting that DETC likely provides IL-17A to induce epidermal RegIII $\gamma$ upon wounding. In contrast to the wound-healing-promoting properties of RegIII $\gamma$ exerted in WT mice (59), $\beta$-defensin 3 improved wound closure in $I l 17 a^{-/-}$but did not significantly affect wound healing in WT mice, at least in our model system. In addition, lower doses of $\beta$-defensin 3 were not sufficient to fully restore wound healing, suggesting that treatment with $\beta$-defensin 3 at higher concentrations may compensate for the lack of RegIII $\gamma$ induction in $\mathrm{Il17}^{-/-}$mice and that under normal conditions in a WT host, $\beta$-defensin 3 and RegIII $\gamma$ likely act in concert to regulate wound-healing responses. We conclude that induction of $\beta$-defensin $3, \mathrm{~S} 100 \mathrm{~A} 8$, and RegIII $\gamma$ in keratinocytes may be the underlying mechanism of the wound-healing-promoting properties of DETC-derived IL-17A. IL-17A is not constitutively produced by DETC, but upon activation, DETC-derived IL-17A likely plays a role in responses to tissue damage, whereas homeostatic AMP expression is likely controlled by other mechanisms.

Skin injury requires the reestablishment of the biochemical (antimicrobial) and the physical skin barriers, which are restored during the inflammatory and proliferative phases of wound healing, yet interaction between these 2 phases exists. Findings from this study and others demonstrate that IL-17A induces not only inflammatory but also proliferative cell responses $(38,59)$ and exerts effects on various genes relevant for wound healing including $\beta$-defensins, Reg proteins, CXCL1, and matrix metalloproteinases $(59,77-79)$. Thus, it is possible that the woundhealing-promoting properties of DETC-derived IL-17A may operate not only through induction of AMP but also by other target genes that may induce multiple cellular and molecular events to promote the wound-healing response. These pleiotropic actions of IL-17A may explain the profound effects on wound healing observed upon treatment of wounds with rIL-17 or with blocking IL-17 antibodies. In addition, the recombinant IL-17A used in our restoration experiments showed functional effects on the wound-healing response. Although the lowest amount of recom- 
binant IL-17A tested was not sufficient to promote wound healing in $I l 17 \mathrm{a}^{-/-}$wounds, it should be noted that the bioavailability/ activity for endogenous and exogenous IL-17A may be different or, alternatively, that additional factors from WT DETC may mediate optimal wound healing together with IL-17A.

The significance of our findings is emphasized by several observations made in humans. Resident T cells, consisting of $\alpha \beta$ and $\gamma \delta \mathrm{T}$ cells (22), are present in human skin and exceed the numbers of circulating $\mathrm{T}$ cells in the human body, suggesting a highly relevant and underestimated function for cutaneous immunity (80). In fact, skin-resident $\mathrm{T}$ cells are dysfunctional in nonhealing wounds (22), IL-17A is decreased at wound sites from severe burn wound patients who are highly susceptible to infections and sepsis (81), and patients with genetic mutations limiting the levels of IL-17A suffer from reoccurring mucocutaneous infections and ulcers $(82,83)$. This raises the possibility that repair of acute wounds in those patients may be improved by therapeutic targeting of skin-resident $\mathrm{T}$ cells to produce IL-17A or by local administration of recombinant IL-17A. Based on our findings of delayed wound closure in IL-17A-deficient mice and mice treated with blocking IL-17A antibodies, future studies are necessary to evaluate whether patients receiving drugs to block the IL-17 pathway, such as those suffering from psoriasis, also exhibit wound-healing defects. Mechanical skin injury is a trigger for initiation of psoriatic plaques; however, the molecular mechanisms are not fully understood. IL-17A induced by skin injury may initiate an aberrant inflammatory response and hyperproliferation in the skin of susceptible individuals, which may subsequently trigger the development of psoriatic plaques. Whether other forms of skin damage, for example, through skin irritants or excessive sun exposure, can also cause IL-17 production by DETC is currently under investigation. Results from our study may provide novel insights into the pathophysiology of psoriasis and other inflammatory skin diseases as well as provide insight into the development of new therapies.

\section{Methods}

Mice. C57BL/6 and Tord ${ }^{-/-}$mice on the C57BL/6 background were purchased from The Jackson Laboratory. $I l 17 a^{-/-}$mice were provided by $\mathrm{Y}$. Iwakura (University of Tokyo, Tokyo, Japan) (84) and K. Ley (La Jolla Institute for Allergy and Immunology, La Jolla, California, USA). C57BL/6, $I l 17 \mathrm{a}^{-/}$, and $\mathrm{Tcrd} \mathrm{C}^{-/-}$mice were bred at The Scripps Research Institute, and all animals were housed in specific pathogen-free conditions according to The Scripps Research Institute IACUC guidelines.

Skin cell preparation. DETC were freshly isolated from mouse skin as previously described (21). Either whole epidermal cell suspensions or DETC purified by FACS sorting based on $\mathrm{V} \gamma 3$ and Thy 1.2 expression were used in experiments, unless otherwise indicated. For generation of DETC shortterm cell lines, epidermal cells were cultured in the presence of $5 \mathrm{U} / \mathrm{ml}$ IL-2, as previously described (16). Primary keratinocytes were isolated and maintained as described previously (85).

Activation assays. Epidermal cells or FACS-sorted DETC were cultured in complete DMEM or RPMI containing $10 \%$ FCS. Approximately $0.5-1 \times 10^{6} / \mathrm{ml}$ cells were stimulated with various concentrations of plate-bound anti-CD $3 \varepsilon$ antibody (500A2), IL-23 (10 ng/ml), or IL-1 $\beta(10 \mathrm{ng} / \mathrm{ml})$ or a combination thereof, as stated in figure legends. For some experiments, DETC were pretreated with $1 \mu \mathrm{g} / \mathrm{ml}$ CsA (Calbiochem) or DMSO vehicle control before TCR stimulation. FACS-sorted DETC were stimulated with anti-CD3ع $(10 \mu \mathrm{g} / \mathrm{ml})$ for 3 hours for mRNA analyses. Low dose IL-2 $(5 \mathrm{U} / \mathrm{ml})$ was present for activation assays using DETC short-term cell lines. For proliferation assays, freshly isolated and FACS-sorted DETC were stimulated for 18-24 hours before addition of $0.5 \mu \mathrm{Ci} /$ well $\left[{ }^{3} \mathrm{H}\right]$ thymidine (MP Biomedicals). Samples were harvested 18 hours later and $\left[{ }^{3} \mathrm{H}\right]$ thymidine incorporation was measured using a Beckman LS181 scintillation counter (Beckman Coulter). For JAML costimulation experiments, anti-JAML antibodies $(10 \mu \mathrm{g} / \mathrm{ml})(29)$ together with anti-CD3 $\varepsilon$ antibodies $(0.5 \mu \mathrm{g} / \mathrm{ml})$ were diluted in ELISA coating buffer ( $50 \mathrm{mM}$ Tris, $150 \mathrm{mM} \mathrm{NaCl}$; $\mathrm{pH}$ 8.0) and immobilized to individual wells of 96-well flat-bottom microtiter ELISA plates. For analyses of secreted cytokines, supernatants were removed at various time points and immediately stored at $-20^{\circ} \mathrm{C}$ until use. Supernatants from FACS-sorted DETC were analyzed for presence of IL-17A, TNF- $\alpha$, or IFN- $\gamma$ by ELISA (eBioscience). For detection of intracellular cytokines, cells were incubated with Brefeldin A $(5 \mu \mathrm{g} / \mathrm{ml}-10 \mu \mathrm{g} / \mathrm{ml}$ ) and Monensin (eBioscience, 1:1000) for up to 1 hour prior to stimulation and for an additional 3 to 8 hours during stimulation. For 18- and 24-hour time points, Brefeldin A and Monensin were added to cells for the last 3-5 hours of stimulation. Primary murine keratinocytes were stimulated with $5 \mathrm{ng} / \mathrm{ml}$ recombinant IL-17 (eBioscience) for different time points, as indicated.

Statistics. Data represent mean \pm SEM and are representative of 3 independent experiments unless otherwise indicated. Statistical significance was measured using 2-tailed Student's $t$ test or 2-way ANOVA, as described in figure legends. $P$ of $\leq 0.05$ was considered significant.

Study approval. All studies were reviewed and approved by the IACUC at The Scripps Research Institute.

For additional details, see Supplemental Methods and Supplemental Table 1.

\section{Acknowledgments}

We thank Yoichiro Iwakura and Klaus Ley for providing $\mathrm{Ill} \mathrm{a}^{-/-}$ mice; Julie Jameson, Charles Surh, and Karsten Sauer for advice; Kitty Cheung and Kwesi Frimpong-Boateng for help with mouse procedures; and Kevin Sendaydiego and Ivan Ye for technical assistance. We thank Charlotte M. Bonefeld and Klaus Ley for critical reading of the manuscript. This work was supported by NIH grants R01AI036964 (to W.L. Havran), R01AI067460 and R01A1099728 (to K. Mowen), and a research award from the Deutsche Dermatologische Gesellschaft (DDG) and Arbeitskreis Dermatologische Forschung (ADF) (to A.S. MacLeod). A.S. MacLeod is supported by NIH training grant 5T32AI007244. This is manuscript 21832 from The Scripps Research Institute.

Received for publication March 21, 2013, and accepted in revised form August 1, 2013.

Address correspondence to: Wendy L. Havran, The Scripps Research Institute, Department of Immunology and Microbial Science, 10550 N. Torrey Pines Road, IMM-8, La Jolla, California 92037, USA. Phone: 858.784.2742; Fax: 858.784.8179; E-mail: havran@scripps.edu.
1. Elias PM. Skin barrier function. Curr Allergy Asthma
Rep. 2008;8(4):299-305.
2. Braff MH, Gallo RL. Antimicrobial peptides: an
essential component of the skin defensive barrier.
Curr Top Microbiol Immunol. 2006;306:91-110.
3. Buchau AS, Gallo RL. Innate immunity and antimi- crobial defense systems in psoriasis. Clin Dermatol. 2007;25(6):616-624.

4. Buchau AS, et al. The host defense peptide cathelicidin is required for NK cell-mediated suppression of tumor growth. J Immunol. 2010;184(1):369-378.

5. Baum CL, Arpey CJ. Normal cutaneous wound heal- ing: clinical correlation with cellular and molecular events. Dermatol Surg. 2005;31(6):674-686.

6. Gailit J, Clark RA. Wound repair in the context of extracellular matrix. Curr Opin Cell Biol. 1994; 6(5):717-725.

7. Strecker-McGraw MK, Jones TR, Baer DG. Soft tis- 
sue wounds and principles of healing. Emerg Med Clin North Am. 2007;25(1):1-22.

8. Kolls JK, McCray PB Jr, Chan YR. Cytokine-mediated regulation of antimicrobial proteins. Nat Rev Immunol. 2008;8(11):829-835.

9. Lande R, et al. Plasmacytoid dendritic cells sense self-DNA coupled with antimicrobial peptide. Nature. 2007;449(7162):564-569.

10. Takamiya M, Biwasaka H, Saigusa K, Nakayashiki $\mathrm{N}$, Aoki Y. Wound age estimation by simultaneous detection of 9 cytokines in human dermal wounds with a multiplex bead-based immunoassay: an estimative method using outsourced examinations. Leg Med (Tokyo). 2009;11(4):186-190.

11. Dorschner RA, et al. Cutaneous injury induces the release of cathelicidin anti-microbial peptides active against group A Streptococcus. J Invest Dermatol. 2001;117(1):91-97.

12. Schauber J, et al. Injury enhances TLR 2 function and antimicrobial peptide expression through a vitamin D-dependent mechanism. J Clin Invest. 2007; 117(3):803-811.

13. Sorensen OE, et al. Injury-induced innate immune response in human skin mediated by transactivation of the epidermal growth factor receptor. J Clin Invest. 2006;116(7):1878-1885.

14. Rodriguez-Martin M, et al. Expression of epidermal CAMP changes in parallel with permeability barrier status. J Invest Dermatol. 2011;131(11):2263-2270.

15. Garman RD, Doherty PJ, Raulet DH. Diversity, rearrangement, and expression of murine $\mathrm{T}$ cell $\gamma$ genes. Cell. 1986;45(5):733-742.

16. Sharp LL, Jameson JM, Cauvi G, Havran WL. Dendritic epidermal $\mathrm{T}$ cells regulate skin homeostasis through local production of insulin-like growth factor 1. Nat Immunol. 2005;6(1):73-79.

17. Girardi M, et al. Resident skin-specific $\gamma \delta \mathrm{T}$ cells provide local, nonredundant regulation of cutaneous inflammation. J Exp Med. 2002;195(7):855-867.

18. Girardi M, et al. Regulation of cutaneous malignancy by $\gamma \delta$ T cells. Science. 2001;294(5542):605-609.

19. Girardi M, Lewis JM, Filler RB, Hayday AC, Tigelaar RE. Environmentally responsive and reversible regulation of epidermal barrier function by $\gamma \delta \mathrm{T}$ cells. J Invest Dermatol. 2006;126(4):808-814.

20. Cho JS, et al. IL-17 is essential for host defense against cutaneous Staphylococcus aureus infection in mice. J Clin Invest. 2010;120(5):1762-1773.

21. Jameson J, et al. A role for skin $\gamma \delta \mathrm{T}$ cells in wound repair. Science. 2002;296(5568):747-749.

22. Toulon A, et al. A role for human skin-resident $\mathrm{T}$ cells in wound healing. J Exp Med. 2009;206(4):743-750.

23. Havran WL, Jameson JM. Epidermal T cells and wound healing. J Immunol. 2010;184(10):5423-5428.

24. Jameson JM, Cauvi G, Witherden DA, Havran WL. A keratinocyte-responsive $\gamma \delta$ TCR is necessary for dendritic epidermal $\mathrm{T}$ cell activation by damaged keratinocytes and maintenance in the epidermis. J Immunol. 2004;172(6):3573-3579.

25. Havran WL, Chien YH, Allison JP. Recognition of self antigens by skin-derived $T$ cells with invariant $\gamma \delta$ antigen receptors. Science. 1991;252(5011):1430-1432.

26. Matsue H, Cruz PD Jr, Bergstresser PR, Takashima A. Profiles of cytokine mRNA expressed by dendritic epidermal T cells in mice. J Invest Dermatol. 1993; 101(4):537-542.

27. Boismenu R, Feng L, Xia YY, Chang JC, Havran WL. Chemokine expression by intraepithelial $\gamma \delta \mathrm{T}$ cells. Implications for the recruitment of inflammatory cells to damaged epithelia. J Immunol. 1996; 157(3):985-992.

28. Macleod AS, Havran WL. Functions of skin-resident $\gamma \delta$ T cells. Cell Mol Life Sci. 2011;68(14):2399-2408.

29. Witherden DA, et al. The junctional adhesion molecule JAML is a costimulatory receptor for epithelial $\gamma \delta$ T cell activation. Science. 2010;329(5996):1205-1210.

30. Cai Y, et al. Pivotal role of dermal IL-17-producing $\gamma \delta \mathrm{T}$ cells in skin inflammation. Immunity. 2011;
35(4):596-610.

31. Gray EE, Suzuki K, Cyster JG. Cutting edge: Identification of a motile IL-17-producing $\gamma \delta \mathrm{T}$ cell population in the dermis. JImmunol. 2011;186(11):6091-6095.

32. Martin B, Hirota K, Cua DJ, Stockinger B, Veldhoen M. Interleukin-17-producing $\gamma \delta \mathrm{T}$ cells selectively expand in response to pathogen products and environmental signals. Immunity. 2009;31(2):321-330.

33. Sutton CE, Lalor SJ, Sweeney CM, Brereton CF, Lavelle EC, Mills KH. Interleukin-1 and IL-23 induce innate IL-17 production from $\gamma \delta$ T cells, amplifying Th17 responses and autoimmunity. Immunity. 2009;31(2):331-341.

34. Sumaria N, et al. Cutaneous immunosurveillance by self-renewing dermal $\gamma \delta$ T cells. J Exp Med. 2011; 208(3):505-518.

35. Jensen JM, Schutze S, Forl M, Kronke M, Proksch E. Roles for tumor necrosis factor receptor p55 and sphingomyelinase in repairing the cutaneous permeability barrier. J Clin Invest. 1999; 104(12):1761-1770

36. Shinozaki M, Okada Y, Kitano A, Ikeda K, Saika $\mathrm{S}$. Impaired cutaneous wound healing with excess granulation tissue formation in TNF $\alpha$-null mice. Arch Dermatol Res. 2009;301(7):531-537.

37. Gregorio J, et al. Plasmacytoid dendritic cells sense skin injury and promote wound healing through type I interferons. J Exp Med. 2010;207(13):2921-2930.

38. Du F, et al. Expression of snail in epidermal keratinocytes promotes cutaneous inflammation and hyperplasia conducive to tumor formation. Cancer Res. 2011;70(24):10080-10089.

39. Iwakura Y, Ishigame H, Saijo S, Nakae S. Functional specialization of interleukin-17 family members. Immunity. 2011;34(2):149-162.

40. Shi X, et al. IL-17A upregulates keratin 17 expression in keratinocytes through STAT1- and STAT3dependent mechanisms. J Invest Dermatol. 2011; 131(12):2401-2408.

41. Mori R, Shaw TJ, Martin P. Molecular mechanisms linking wound inflammation and fibrosis: knockdown of osteopontin leads to rapid repair and reduced scarring. J Exp Med. 2008;205(1):43-51.

42. Komori HK, et al. Cutting Edge: Dendritic epidermal $\gamma \delta \mathrm{T}$ cell ligands are rapidly and locally expressed by keratinocytes following cutaneous wounding. J Immunol. 2012;188(7):2972-2976.

43. Clipstone NA, Crabtree GR. Identification of calcineurin as a key signalling enzyme in T-lymphocyte activation. Nature. 1992;357(6380):695-697.

44. Ivanov II, et al. The orphan nuclear receptor ROR $\gamma t$ directs the differentiation program of proinflammatory IL-17+ T helper cells. Cell. 2006; 126(6):1121-1133.

45. Veldhoen M, et al. The aryl hydrocarbon receptor links TH17-cell-mediated autoimmunity to environmental toxins. Nature. 2008;453(7191):106-109.

46. Yang XO, et al. T helper 17 lineage differentiation is programmed by orphan nuclear receptors $\mathrm{ROR} \alpha$ and ROR\%. Immunity. 2008;28(1):29-39.

47. Yang XO, et al. STAT3 regulates cytokine-mediated generation of inflammatory helper T cells. J Biol Chem. 2007;282(13):9358-9363.

48. Wen Z, Zhong Z, Darnell JE Jr. Maximal activation of transcription by Stat 1 and Stat 3 requires both tyrosine and serine phosphorylation. Cell. 1995; 82(2):241-250

49. Kadow S, et al. Aryl hydrocarbon receptor is critical for homeostasis of invariant $\gamma \delta \mathrm{T}$ cells in the murine epidermis. J Immunol. 2011;187(6):3104-3110.

50. Liang SC, et al. Interleukin (IL)-22 and IL-17 are coexpressed by Th17 cells and cooperatively enhance expression of antimicrobial peptides. J Exp Med. 2006;203(10):2271-2279.

51. Taylor KR, Mills RE, Costanzo AE, Jameson JM. $\gamma \delta$ T cells are reduced and rendered unresponsive by hyperglycemia and chronic TNF $\alpha$ in mouse models of obesity and metabolic disease. PLoS One. 2010;5(7):e11422

52. Turchinovich G, Hayday AC. Skint-1 identifies a common molecular mechanism for the development of interferon- $\gamma$-secreting versus interleukin17-secreting $\gamma \delta$ T cells. Immunity. 2011;35(1):59-68.

53. Ribot JC, et al. CD27 is a thymic determinant of the balance between interferon- $\gamma$ - and interleukin 17 -producing $\gamma \delta$ T cell subsets. Nat Immunol. 2009; 10(4):427-436.

54. Ribot JC, et al. Cutting edge: adaptive versus innate receptor signals selectively control the pool sizes of murine IFN- $\gamma$ - or IL-17-producing $\gamma \delta$ T cells upon infection. J Immunol. 2010;185(11):6421-6425.

55. Rahman A, Fahlgren A, Sundstedt C, Hammarstrom S, Danielsson A, Hammarstrom ML. Chronic colitis induces expression of $\beta$-defensins in murine intestinal epithelial cells. Clin Exp Immunol. 2011;163(1):123-130.

56. Taylor KR, et al. Recognition of hyaluronan released in sterile injury involves a unique receptor complex dependent on Toll-like receptor 4, CD44, and MD-2.J Biol Chem. 2007;282(25):18265-18275.

57. Heilborn JD, et al. The cathelicidin anti-microbial peptide LL-37 is involved in re-epithelialization of human skin wounds and is lacking in chronic ulcer epithelium. J Invest Dermatol. 2003;120(3):379-389.

58. Ahrens K, et al. Mechanical and metabolic injury to the skin barrier leads to increased expression of murine beta-defensin-1, -3, and -14.J Invest Dermatol. 2011;131(2):443-452

59. Lai Y, et al. The antimicrobial protein REG3A regulates keratinocyte proliferation and differentiation after skin injury. Immunity. 2012;37(1):74-84.

60 . Thorey IS, et al. The Ca2+-binding proteins S100A8 and S100A9 are encoded by novel injury-regulated genes. J Biol Chem. 2001;276(38):35818-35825.

61. Sasaki JR, Zhang Q, Schwacha MG. Burn induces a Th-17 inflammatory response at the injury site. Burns. 2011;37(4):646-651.

62. Havran WL. A role for epithelial $\gamma \delta \mathrm{T}$ cells in tissue repair. Immunol Res. 2000;21(2-3):63-69.

63. Tschachler E, Steiner G, Yamada H, Elbe A, Wolff K, Stingl G. Dendritic epidermal T cells: activation requirements and phenotypic characterization of proliferating cells. J Invest Dermatol. 1989; 92(5):763-768.

64. Boyden LM, et al. Skint1, the prototype of a newly identified immunoglobulin superfamily gene cluster, positively selects epidermal $\gamma \delta \mathrm{T}$ cells. Nat Genet. 2008;40(5):656-662.

65 . Jensen KD, et al. Thymic selection determines $\gamma \delta \mathrm{T}$ cell effector fate: antigen-naive cells make interleukin-17 and antigen-experienced cells make interferon $\gamma$. Immunity. 2008;29(1):90-100.

66. Brogdon JL, Leitenberg D, Bottomly K. The potency of TCR signaling differentially regulates NFATc/p activity and early IL-4 transcription in naive CD4+ T cells. J Immunol. 2002; 168(8):3825-3832.

67. Leitenberg D, Bottomly K. Regulation of naive $\mathrm{T}$ cell differentiation by varying the potency of TCR signal transduction. Semin Immunol. 1999; 11(4):283-292.

68. Leitenberg D, Boutin Y, Constant S, Bottomly K. $\mathrm{CD} 4$ regulation of TCR signaling and T cell differentiation following stimulation with peptides of different affinities for the TCR. J Immunol. 1998; 161(3):1194-1203.

69. Chodaczek G, Papanna V, Zal MA, Zal T. Body-barrier surveillance by epidermal $\gamma \delta$ TCRs. Nat Immunol. 2012;13(3):272-282.

70. Hayday A, Tigelaar R. Casting new light on the TCR. Nat Immunol. 2012;13(3):209-211.

71. Taylor KR, Mills RE, Costanzo AE, Jameson JM. Gammadelta $T$ cells are reduced and rendered unresponsive by hyperglycemia and chronic TNF $\alpha$ in mouse models of obesity and metabolic disease. PLoS One. 2010;5(7):e11422. 
72. Ely LK, Fischer S, Garcia KC. Structural basis of receptor sharing by interleukin 17 cytokines. Nat Immunol. 2009;10(12):1245-1251.

73. Toy D, et al. Cutting edge: interleukin 17 signals through a heteromeric receptor complex. JImmunol. 2006;177(1):36-39.

74. Nakatsuji T, Gallo RL. Antimicrobial peptides: old molecules with new ideas. J Invest Dermatol. 2012; 132(3):887-895.

75. Niyonsaba F, et al. Antimicrobial peptides human $\beta$-defensins stimulate epidermal keratinocyte migration, proliferation and production of proinflammatory cytokines and chemokines. J Invest Dermatol. 2007;127(3):594-604.

76 . Yang $D$, et al. $\beta$-defensins: linking innate and adaptive immunity through dendritic and T cell CCR6.
Science. 1999;286(5439):525-528.

77. Datta S, et al. IL-17 regulates CXCL1 mRNA stability via an AUUUA/tristetraprolin-independent sequence. J Immunol. 2010;184(3):1484-1491.

78. Hartupee J, Liu C, Novotny M, Li X, Hamilton T. IL-17 enhances chemokine gene expression through mRNA stabilization. J Immunol. 2007; 179(6):4135-4141.

79. Sun D, Novotny M, Bulek K, Liu C, Li X, Hamilton $\mathrm{T}$. Treatment with IL-17 prolongs the half-life of chemokine CXCL1 mRNA via the adaptor TRAF5 and the splicing-regulatory factor SF2 (ASF). Nat Immunol. 2011;12(9):853-860.

80. Clark RA, et al. The vast majority of CLA $+\mathrm{T}$ cells are resident in normal skin. J Immunol. 2006 176(7):4431-4439.
81. Inatsu A, et al. Lack of Th17 cell generation in patients with severe burn injuries. J Immunol. 2011; 187(5):2155-2161.

82. Ma CS, et al. Deficiency of Th17 cells in hyper IgE syndrome due to mutations in STAT3. J Exp Med. 2008;205(7):1551-1557.

83. Milner JD, et al. Impaired T(H) 17 cell differentiation in subjects with autosomal dominant hyperIgE syndrome. Nature. 2008;452(7188):773-776.

84. Nakae S, et al. Antigen-specific T cell sensitization is impaired in IL-17-deficient mice, causing suppression of allergic cellular and humoral responses. Immunity. 2002;17(3):375-387.

85. Yano S, Okochi H. Long-term culture of adult murine epidermal keratinocytes. Br J Dermatol. 2005; 153(6):1101-1104. 